\title{
A NOTE ON VON WRIGHT'S FORMULATION OF INTENTIONAL EXPLANATIONS
}

In his book Explanation and Understanding G. H. von Wright is claiming that intentional - or as he says: teleological - explanations are in fact practical inferences "turned upside down" and that the structure of a practical inference (or syllogism) is essentially given by the following schema :

(PS) $\quad A$ intends to bring about $p$.

$A$ considers that he cannot bring about $p$ unless he does $a$.

Therefore $A$ sets himself to do $a .^{1}$

In this note I do not want to discuss the general question how we should analyze the structure of intentional explanations. ${ }^{2}$ My concern here is only an issue which indeed may be of minor importance: the question how the second premise of the schema (PS) should be formulated.

As already mentioned von Wright prefers the following formulation:

$A$ considers that he cannot bring about $p$ unless he does $a$.

And thereby he seems to tie himself down to the view that a given intentional explanation can only be correct if the action to be explained is at least as the agent believes - a necessary condition for his bringing about $p$. Other authors however tend more in direction of a sufficient condition when they instead of (i) choose a formulation like this:

(ii)

$A$ believes that $a$ is a suitable means for him to achieve $p .^{3}$

In a lecture given at Karlsruhe University in the summer of 1975 von Wright tried to defend his formulation (i) against this alternative view. One could ask however on which occasions when $A$ intends to bring about $p$ he in fact performs the action $a$. And then one immediately realizes that both formulations are not quite correct if they are taken seriously. Let us first have a look at von Wright's formulation (i) and let us consider for illustration the following example of an intentional explanation:

(IE) Smith crosses the street because he intends to get some cigarettes in the cigar store.

Erkenntnis 14 (1979) 349-353. 0165-0106/79/0143-0349 \$00.50

Copyright (C) 1979 by D. Reidel Publishing Co., Dordrecht, Holland, and Boston, U.S.A. 
According to von Wright's view this explanation more explicitly formulated should run like this:

(IE') Smith intends to get some cigarettes.

Smith considers that he cannot get any cigarettes unless he crosses the street.

Therefore Smith crosses the street. ${ }^{4}$

But in this form the explanation (IE) is at least problematic. In almost all cases where we should assume this explanation to be correct it is highly improbable that Smith in fact believes that he will get no cigarettes unless he crosses the street. For in any not quite unusual situation there will be as Smith well knows - a lot of other means for him to achieve the same goal. He might for example as well give some money to a boy passing by and ask him to go over and buy him some cigarettes or he himself might walk on another five minutes to the next cigarette slot-machine.

Thus we have to realize that usually if $A$ does $a$ in order to bring about $p$ it is not the case that $a$ is a necessary condition for bringing about $p$ or rather that $A$ believes this to be so. So the formulation (i) is implausible because there are cases in which a given intentional explanation is correct while there is no true corresponding premise of kind (i).

But on the other hand there are also cases in which a premise of kind (i) is true while the corresponding intentional explanation is not correct. Let us take as an example once again the explanation (IE) and let us assume furthermore that as things are it is indeed true that Smith cannot get any cigarettes unless he crosses the street and that he knows this. Then what would happen if we assume that Smith knows moreover that he has no money in his pockets so that he will not be able to pay? I think that in this case Smith will not cross the street even if he intends to get some cigarettes and considers that he will not get any unless he crosses the street. For as things are Smith will realize that he will not be able to bring this action to an end, i.e., that he will get no cigarettes even if he crosses the street because after stepping in the cigar store he will not be able to pay.

The difficulty in this last case seems to me to be this. Smith indeed knows that in the given situation he will get no cigarettes unless he crosses the street; but he nevertheless will not be convinced that he will get cigarettes if he performs this action. For his crossing the street is itself not sufficient for him to achieve his goal. Thus the question is whether or not 
those authors are right who in opposition to von Wright prefer formulation (ii).

I believe that they are not; the latter formulation is no less problematic than (i). For as already mentioned, even in the case just discussed crossing the street is by no means sufficient for Smith to get cigarettes. The fact is rather that Smith has to perform quite a number of actions by which (in all probability ${ }^{5}$ ) he will achieve his goal: first he has to cross the street, then he has to enter the tobacconist's shop and ask for cigarettes, then he has to pay, and not until he finally takes the cigarettes and puts them into his pocket he will have achieved what he wanted.

These considerations show that even if we want to explain a single action it is not only this action that is at issue but the whole course of all actions which are necessary and sufficient to bring about $p$. Only if $A$ believes that he is able to perform all actions of this course will he also set himself to perform each single one. If for the sake of simplicity we here take a course of actions simply to be a certain finite set $\left\{a_{1}, \ldots, a_{n}\right\}$ of some simultaneous or successive actions therefore the following consideration suggests itself: If $A$ intends to bring about $p$ then he will do $a$ if there is a course of actions $C=\left\{a_{1}, \ldots, a_{n}\right\}$ with $a \in C$ (i.e. $a=a_{i}$ for some $i=$ $1, \ldots, n)$, if $A$ believes that under the given circumstances $C$ in all probability will bring about $p$ and that under the given circumstances the alternative course of actions $C^{\prime}=\left\{a_{1}, \ldots, a_{i-1}, a_{i+1}, \ldots, a_{n}\right\}$ in all probability will not bring about $p$ and if $A$ believes that in the given situation he will be able to perform all actions of $C$.

If this consideration is correct the formulation of the second premise of the schema (PS) however has to be much more complex than the corresponding premise in von Wright's account. In my opinion it seems to be reasonable to replace the formulations (i) and (ii) by the following three conditions:

(iii)

$A$ believes that there is a course of actions $C=\left\{a_{1}, \ldots, a_{n}\right\}$ with $a=a_{i}$ for some $i=1, \ldots, n$ which under the given circumstances in all probability will bring about $p$.

(iv) $A$ believes that under the given circumstances the alternative course of actions $C^{\prime}=\left\{a_{1}, \ldots, a_{i-1}, a_{i+1}, \ldots, a_{n}\right\}$ in all probability will not bring about $p$.

(v) $A$ believes that in the given situation he is able to perform all actions of $C$. 
These three conditions in any case show that the formulations (i) and (ii) are not completely wrong. For even if these formulations are in themselves inadequate there surely is a certain correspondence between formulation (i) and condition (iv) and formulation (ii) and condition (iii). Even the conditions (iii)-(v) however are not quite sufficient for our purposes. For even if $A$ intends to bring about $p$ and the conditions (iii)-(v) are satisfied $A$ will not do $a$ if there is something that he prefers to $p$ and that he believes to be incompatible with at least one of the actions of $C$. And a similar consideration holds for the case that $A$ believes that there is another course of actions $C^{*}$ with $a \notin C^{*}$ which also satisfies the conditions (iii)-(v) and which $A$ under the given circumstances would prefer to $C$. $^{8}$

So explicitly formulated I think the schema (PS) should run like this:

(PS') (1) $A$ intends to bring about $p$.

(2) $A$ believes that there is a course of actions $C=\left\{a_{1}, \ldots, a_{n}\right\}$ with $a=a_{i}$ for some $i=1, \ldots, n$ which under the given circumstances in all probability will bring about $p$.

(3) $\boldsymbol{A}$ believes that under the given circumstances the alternative course of actions $C^{\prime}=\left\{a_{1}, \ldots, a_{i-1}, a_{i+1}, \ldots, a_{n}\right\}$ in all probability will not bring about $p$.

(4) $A$ believes that in the given situation he is able to perform all actions of $C$.

(5) There is no course of actions $C^{*}$ with $a \notin C^{*}$ which also satisfies the conditions (2)-(4) and which $A$ under the given circumstances would prefer to $C$.

(6) There is nothing that $A$ prefers to $p$ and that $A$ believes to be incompatible with at least one action of $C$.

(7) Therefore $A$ sets himself to do $a$.

\section{Osnabrück}

NOTES

1 Explanation and Understanding, London 1971, p. 96; cf. also 'Determinism and the Study of Man', in J. Manninen and R. Tuomela (eds.), Essays on Explanation and Understanding, Dordrecht 1976, p. 417.

2 For this point see Beckermann, Gründe und Ursachen, Kronberg/Ts. 1977 and Beckermann, 'Intentionale vs. kausale Handlungserklärungen', in H. Lenk (ed.), Handlungstheorien-interdisziplinär, Band 2, München 1979. 
3 Cf. for example P. M. Churchland, 'The Logical Character of Action-Explanations', The Philosophical Review 79 (1970), p. 216 and Beckermann, Gründe und Ursachen ch. 4.

"Here the conclusion runs "Therefore Smith crosses the street" instead of "Therefore Smith sets himself to cross the street" because if we have to explain an action we already know that it took place.

5 That here the clause "in all probability" is necessary can be shown once again with the help of the cigarette example. For even if Smith crosses the street, enters the tobacconist's shop and has enough money in his pockets he cannot be sure that he will get cigarettes. For perhaps the tobacconist just has run short of cigarettes. In general therefore Smith can only be convinced that in all probability his actions will have the intended result.

${ }^{6} \mathrm{Cf}$. the discussion of the formulation (i) above and also Churchland, 'The Logical Character of Action-Explanations', pp. 217-221, Beckermann, Gründe und Ursachen, ch. 7 and Beckermann, 'Intentionale vs. kausale Handlungserklärungen', sec. 7.

Manuscript received 25 August 1978 